\title{
Perinatal Blood Aspiration Syndrome
}

National Cancer Institute

\section{Source}

National Cancer Institute. Perinatal Blood Aspiration Syndrome. NCI Thesaurus. Code C101320.

Respiratory distress in the newborn due to inhalation of blood; this is an unusual event and is sometimes linked to the non passage of meconium before delivery or mothers with antepartum hemorrhage. 